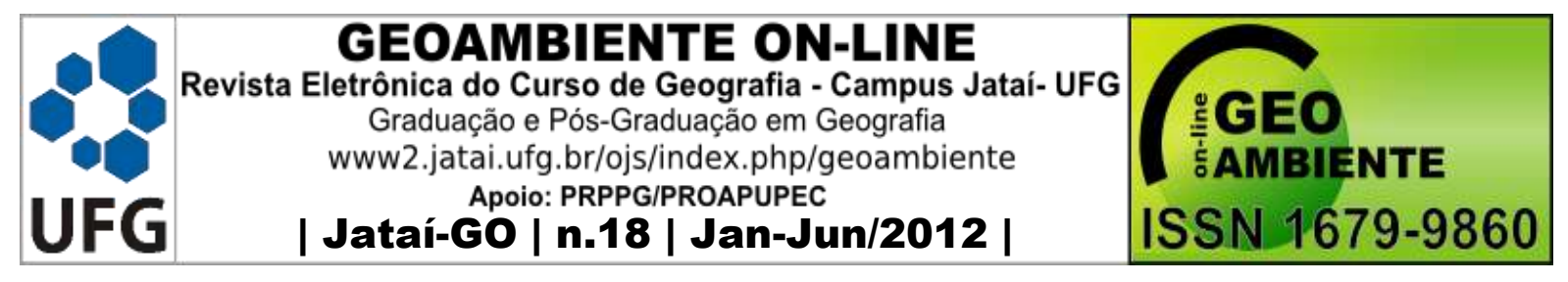

\title{
O TURISMO E AS QUESTÕES SOCIOAMBIENTAIS: UMA DISCUSSÃO SOBRE AS TRANSFORMAÇÕES NO LITORAL DO IGUAPE-CE
}

\author{
Tatiane Rodrigues Carneiro' ${ }^{1}$, Tiago Estevam Gonçalves ${ }^{2}$ \\ (1 - Universidade Federal do Ceará, Mestre em Desenvolvimento e Meio Ambiente, \\ tatianecarneiro@gmail.com 2 - Professor do Instituto Federal de Educação, Ciência e \\ Tecnologia do Ceará - IFCE, Mestre em Geografia Universidade Federal do Ceará, \\ tiagoestevam@ifce.edu.br $)$
}

\section{Resumo}

As questões ambientais estão diretamente ligadas à degradação dos ecossistemas naturais, como poluição de lagoas, rios e mares, diminuição da biodiversidade vegetal e animal, ocupação de áreas vulneráveis, dentre outras. Desta forma, o estudo das transformações socioambientais geradas pelo turismo em determinadas áreas são de grande relevância. Assim, o presente estudo pretende apresentar e analisar as principais transformações socioambientais geradas pelo turismo no litoral do Iguape, localizado no município de Aquiraz, no estado do Ceará, utilizar-se-á para tal finalidade de uma abordagem interdisciplinar, uma vez que o meio ambiente é algo que deve ser estudado através da ótica de vários especialistas, pois se entende que o meio ambiente é uma totalidade.

Palavras-chave: turismo, socioambiental, meio ambiente, sustentabilidade.

\section{Abstract \\ TOURISM AND THE SOCIAL AND ENVIRONMENTAL MATTERS: A DISCUSSION ON THE CHANGES IN THE COST OF IGUAPE-CE}

The environmental mattres are directly linked to degradation of natural ecosystems such as pollution of lakes, rivers and seas, reduced biodiversity plant and animal, occupation of vulnerable areas. Thus the study of social and environmental transformations generated by tourism in certain areas are of great importance. Thus, this study aims to present and analyze

\footnotetext{
Artigo recebido para publicação em 03 de Outubro de 2011

Artigo aprovado para publicação em 15 de Março de 2012
} 


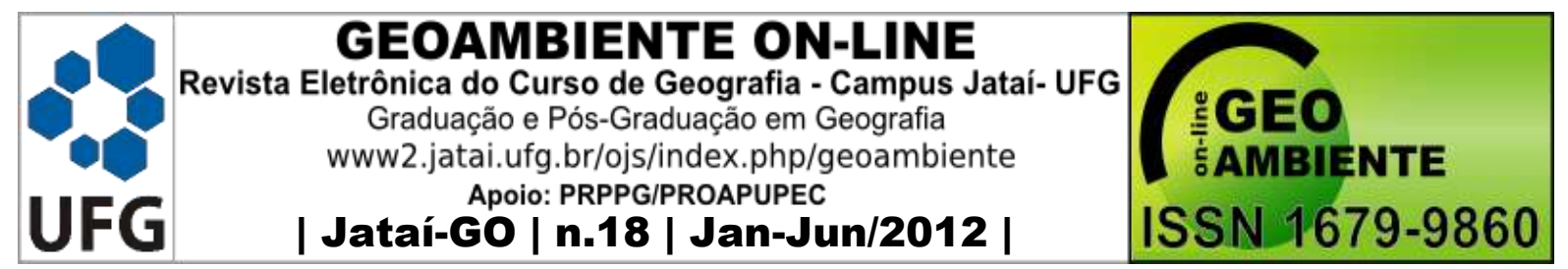

the major social and environmental transformations generated by tourism in coastal Iguape, located in the city of Aquiraz in the state of Ceara, will be used for this purpose an interdisciplinary approach, since the middle environment is something that should be studied through the lens of various specialists, because we understand that the environment is a whole.

Keywords: tourism, social and environmental, environment, sustainability

\section{Resumen}

\section{EL TURISMO Y LOS ASUNTOS SOCIALES Y AMBIENTALES: UMA DISCUSIÓN ACERCA DE LAS TRANSFORMACIONES EN LA COSTA DE IGUAPE-CE}

Los asuntos ambientales están directamente vinculados a la degradacíon ambiental y los ecosistemas naturales, como la contaminación de lagos, rios y mares, la reducción de la biodiversidad vegetal y animal, que ocupa las zonas vulnerables, entre otros. Así, el estúdio de los câmbios sócio-ambientales generados por el turismo em ciertas áreas son de gran importância. Así, este estúdio tiene la intención de presentar y analizar las principales transformaciones sociales y ambientales generadas por el turismo en la costa de Iguape, ubicada em la ciudad de Aquiraz, Estado de Ceará, se utilizará para este fin um enfoque multidisciplinario, ya que el médio ambiente es algo que deve ser estudiado através de la lente de vários expertos, porque entendemos que el médio ambiente es um entero.

Palabras clava: Turismo, social y ambiental, médio ambiente, sustentabilidad.

\section{Introdução}

O turismo pode trazer consigo o desenvolvimento econômico e a geração de emprego e renda, mas pode ser também responsável por grandes transformações socioambientais, relativas à perda da identidade cultural; a degradação e destruição dos recursos naturais e a ausência de perspectivas para os grupos da população local em áreas de destinação turística.

Sempre que o homem apropria-se da natureza, agregando a ela um valor de troca, ou valor de uso, como é o caso da atividade turística, ocorrem uma série de transformações, tanto do ponto de vista social, como ambiental. No turismo, a natureza é apropriada e vendida como um atrativo turístico é o chamado atrativo natural. Praias, serras, rios, lagoas, falésias são apropriadas pelo turismo e muitas vezes exploradas, degradadas e, então, abandonadas pela 


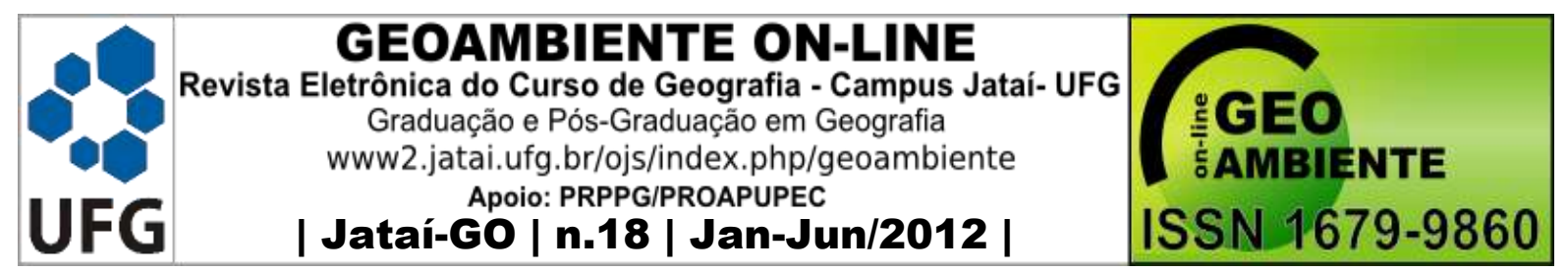

atividade turística, gerando várias transformações socioambientais nos ambientes onde se instala.

As transformações sociais geradas pelo turismo em determinado local relacionam-se ao modo de vida da população, alteração de sua principal atividade econômica, geração de emprego e renda, desemprego, mudança nos hábitos e costumes dos moradores, alteração da dinâmica espacial da região, especulação imobiliária.

As transformações ambientais estão diretamente ligadas à degradação dos ecossistemas naturais, como poluição de lagoas, rios e mares, diminuição da biodiversidade vegetal e animal, ocupação de áreas vulneráveis, como construção de empreendimentos na faixa praial e sobre as dunas e poluição sonora.

Desta forma o estudo das transformações socioambientais geradas pelo turismo em determinadas áreas são de grande relevância. Assim, o presente estudo pretende apresentar e analisar as principais transformações socioambientais geradas pelo turismo no litoral do Iguape, localizado no município de Aquiraz, no estado do Ceará, utilizar-se-á para tal finalidade de uma abordagem interdisciplinar, uma vez que o meio ambiente é algo que deve ser estudado através da ótica de vários especialistas, pois se entende que ele é uma totalidade.

\section{Indicação Teórico-Metodológica}

Visando responder as questões propostas faz-se necessário a utilização de alguns conceitos. Para tanto foram considerados: turismo, atrativo turístico, serviços turísticos turismo sustentável, desenvolvimento sustentável e meio-ambiente.

De acordo com a Organização Mundial de Turismo (OMT, 2001), “Turismo é uma modalidade de deslocamento espacial, que envolve a utilização de algum meio de transporte e ao menos um pernoite no destino; este deslocamento deve ser motivado pelas mais diversas razões, como: lazer, congressos, negócios, saúde etc.".

Para Lima (2006), o turismo é o estudo do homem longe de seu local de residência, da indústria que satisfaz suas necessidades e dos impactos que ambos geram nos ambientes físico, econômico e sociocultural da área receptora.

Para que o turista sinta-se bem, é preciso uma série de fatores, tais como a oferta de serviços turísticos, que são imprescindíveis para a caracterização de um atrativo turístico e que são decisivos no momento da escolha do local visitado por parte do turista. Para isso, as 


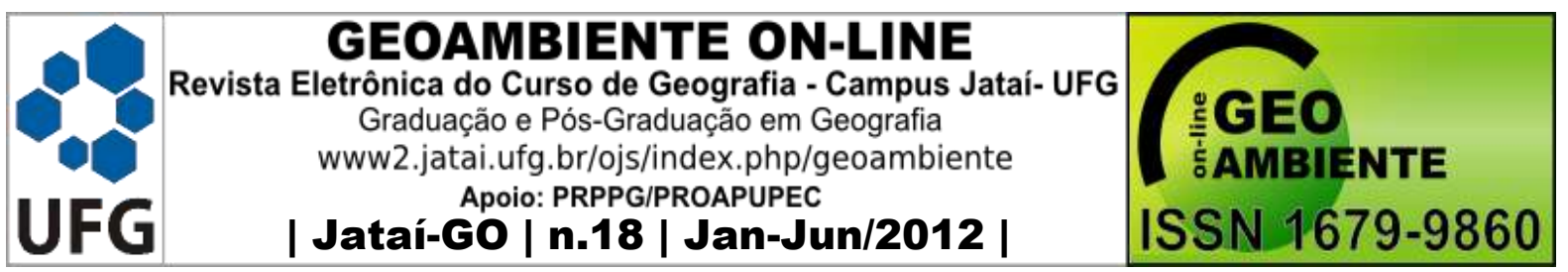

localidades que desejam ter maior visibilidade turística devem investir nestes serviços. E o que são serviços turísticos?

Os serviços turísticos, ainda de acordo com Barretto (2003, p.50):

São aqueles prestados exclusivamente para o turista e que vivem do turismo. É o caso do serviço de guias, ou de serviços como rafting, floating, etc. Segundo a autora, ainda são serviços turísticos aqueles prestados dentro dos equipamentos turísticos (serviços de hotelaria, de agenciamento, de transporte).

No que tange a sustentabilidade, esta tem sido discutida por diversos setores e em vários níveis da sociedade. Dentre as definições mais aceitas sobre desenvolvimento sustentável, podemos destacar Cunha e Guerra (2003, p. 24) segundo os quais:

O desenvolvimento sustentável pode ser definido como um processo contínuo de melhoria das condições de vida, enquanto minimize o uso dos recursos naturais, causando um mínimo de distúrbios ou desequilíbrios ao ecossistema [...] além do mais, deverá ser capaz de satisfazer as necessidades atuais das pessoas sem deteriorar as perspectivas das gerações futuras.

A discussão sobre desenvolvimento sustentável é bastante relevante para a pesquisa, pois, apesar do turismo ser uma atividade que pode gerar trabalho e renda para a comunidade local, ele pode também causar sérios danos ao meio ambiente e a população nativa.

Em meio à discussão sobre turismo sustentável e desenvolvimento sustentável, emerge a necessidade da compreensão do conceito de meio ambiente. De acordo com Veyret (1999 apud Mendonça, 2001, p. 117):

[...] a noção de meio ambiente não recobre somente a natureza, ainda menos a fauna e a flora somente. Este termo designa as relações de interdependência que existem entre o homem, as sociedades e os componentes físicos, químicos, bióticos do meio e integra também seus aspectos econômicos, sociais e culturais.

A partir deste referencial teórico foram consideradas as transformações e a relação ambiente-sociedade existentes no objeto em estudo. A pesquisa foi do tipo bibliográfica e de campo. No primeiro momento da pesquisa realizou-se uma revisão bibliográfica com visitas à Biblioteca Pública Governador Menezes Pimentel, Biblioteca Central da Universidade Federal do Ceará, Biblioteca Central da Universidade Estadual do Ceará, bem como à Superintendência Estadual do Meio Ambiente (SEMACE), à Fundação Cearense de Meteorologia e Recursos Hídricos (FUNCEME), ao Instituto Brasileiro de Geografia e 


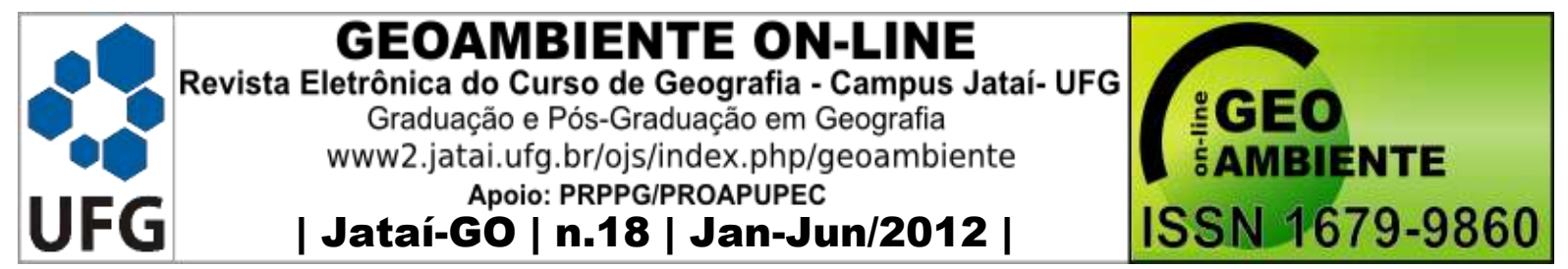

Estatística (IBGE) e ao Instituto de Planejamento Estratégico e Econômico do Ceará (IPECE). No segundo momento foram efetivados trabalhos de campo para a coleta de material. Foram aplicados questionários com os turistas e com a comunidade local e foram realizadas entevistas com os empreendedores locais, para se compreender o ponto de vista de cada um deles acerca do turismo realizado naquela região. A cada visita de campo foram analisadas e comparadas as informações colhidas que subsidiaram a construção da pesquisa.

\title{
Turismo e sustentabilidade
}

O turismo pode ser um eficiente meio para promover uma região, seus valores naturais, sociais e culturais, além de abrir novas perspectivas para o desenvolvimento social, econômico e cultural de uma região, além de promover a melhoria da infraestrutura local, podendo ser um instrumento norteador para o crescimento da localidade, inserindo-a no contexto global.

Porém, o mesmo turismo que pode estimular o desenvolvimento econômico e cultural de uma região, também pode causar sérios danos ao meio ambiente e a sociedade em geral. Como afirma Coriolano (2007, p.26):

\begin{abstract}
o turismo usa e apropria-se da natureza ou ambientes naturais e de ambientes produzidos como cidades, vilas, comunidades, gerando impactos, que podem ser discutidos como uma questão de (in) sustentabilidade social e ambiental. Esta (in) sustentabilidade é produzida pela contradição capitalista, que no turismo toma forma de impactos socioambientais, desequilíbrios sócio-espaciais, especulação imobiliária, ocupação de áreas vulneráveis, descaracterizações ambientais e paisagísticas [...] Mas, apesar disso, não se pode negar o importante significado espacial, social e econômico que o turismo provoca nas sociedades modernas.
\end{abstract}

$\mathrm{Na}$ maioria das vezes, o desenvolvimento do turismo não caminha junto com o planejamento, o que causa grandes prejuízos à população local, que em sua maioria se vê excluída do desenvolvimento econômico e das benesses trazidas pelo turismo, bem como o meio ambiente local é desrespeitado e degradado. O turismo transforma espaços e reorganiza territórios na medida em que seu consumidor tem que se deslocar para consumir o produto ou serviço turístico. Desta forma, tanto as áreas denominadas turísticas como as do seu entorno são reorganizados para atender às novas demandas.

O turismo, de acordo com a Organização Mundial de Turismo (OMT, 2001), "compreende as atividades que realizam as pessoas durante suas viagens e estadias em 


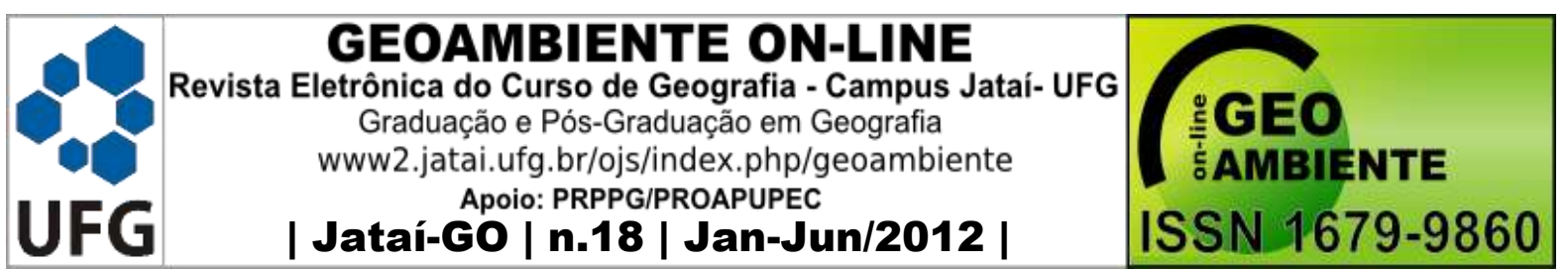

lugares diferentes ao seu entorno habitual, por um período inferior a um ano, com finalidade de lazer, negócios ou outras ”. De acordo com Lima (2006, p.23):

O turismo é um fenômeno social que consiste no deslocamento voluntário e temporário de indivíduos ou grupos de pessoas que, fundamentalmente por motivo de recreação, descanso, cultura ou saúde, saem do seu local de residência habitual para outro, no qual não exercem nenhuma atividade lucrativa ou remunerada, gerando múltiplas inter-relações de importância social, econômica e cultural.

Para que o turismo possa se desenvolver em uma determinada área ou região, são necessários e imprescindíveis os atrativos turísticos. Segundo Barretto (2003), atrativo turístico, "é aquilo que atrai o turista. Do ponto de vista do núcleo, é o recurso, e são, portanto, sinônimos". Ainda segundo Barretto (2003, p.47), recurso turístico é "a matériaprima com a qual se pode planejar turismo num determinado local e divide-se em: naturais (que já existiam na natureza antes da intervenção do homem) e culturais (criados pelo homem, seja a partir da natureza, seja de qualquer outra atividade humana).”.

O turismo é uma atividade econômica que requer uma série de serviços e atrativos para desenvolver-se e que, por conta disso, gera impactos socioambientais nas áreas receptoras. Assim, emerge a necessidade da discussão sobre desenvolvimento sustentável para que possam ser atendidas tanto as demandas sociais como as necessidades básicas ao equilíbrio natural.

Segundo Ansarah (2001, p.30):

O estudo do turismo deve ser direcionado para o desenvolvimento sustentável, conceito essencial para alcançar metas de desenvolvimento sem esgotar os recursos naturais e culturais nem deteriorar o meio ambiente. Entende-se que a proteção do meio ambiente e o êxito do desenvolvimento turístico são inseparáveis.

A discussão sobre desenvolvimento sustentável é bastante relevante para a pesquisa, pois, apesar do turismo ser uma atividade que pode gerar trabalho e renda para a comunidade local, esta atividade pode causar sérios danos ao meio ambiente e à população nativa. Desta forma, faz-se necessário debater também o conceito de Turismo Sustentável.

De acordo com a Organização Mundial de Turismo (OMT, 1995), "turismo sustentável é aquele ecologicamente suportável em longo prazo, economicamente viável, assim como ética e socialmente eqüitativo para as comunidades locais.”.

Segundo Rabahy (1988, p.87): 


\begin{tabular}{|c|c|c|}
\hline & $\begin{array}{l}\text { BIENTE ON-LINE } \\
\text { urso de Geografia - Campus Jataí- UFG } \\
\text { Pós-Graduação em Geografia } \\
\text { g.br/ojs/index.php/geoambiente } \\
\text { : PRPPG/PROAPUPEC } \\
\text { n.18 | Jan-Jun/2012 | }\end{array}$ & $\begin{array}{l}\text { '̇AMBIENTE } \\
\text { ISSN } 1679-9860\end{array}$ \\
\hline
\end{tabular}

Para o turismo ser sustentável no sentido social e cultural, ele deve ser desejado pelos habitantes locais e deve ser percebido como benefício para a maioria da população local, não apenas para uma elite. Ele deve proporcionar empregos para os qualificados assim como para os sem qualificação e gerar oportunidades para os avanços sociais e econômicos.

De acordo com Beni (2004), o Turismo Sustentável, em sua vasta e complexa abrangência, envolve: compreensão dos impactos turísticos; distribuição justa de custos e benefícios; geração de empregos locais diretos e indiretos; fomento de negócios lucrativos; injeção de capital com conseqüente diversificação da economia local; interação com todos os setores e segmentos da sociedade; desenvolvimento estratégico e logístico de modais de transporte; encorajamento ao uso produtivo de terras tidas como marginais (turismo no espaço rural); subvenções para os custos de conservação ambiental.

Desta forma, temos que o turismo para ser sustentável precisa respeitar as características ambientais da localidade onde se desenvolve, suas especificidades, desta forma, o meio ambiente precisa ser respeitado e preservado, emergindo daí a necessidade da compreensão deste termo que é muito utilizado atualmente, mas pouco respeitado, meio ambiente.

Segundo Mendonça (2002, p.21-22), “o meio ambiente atualmente em voga é propalado na perspectiva que engloba o meio natural e o social". Sendo assim, o ser humano está diretamente inserido nas relações que envolvem os aspectos de primeira e segunda natureza. Não se devem separar os elementos físico-naturais dos elementos humano-sociais quando tratamos da questão ambiental, pois estes a constituem e a transformam como um todo, como afirma Leff (2001, p.121) “O recurso natural e a força de trabalho não são entes naturais existentes independentemente do social, mas são já o biológico determinado pelas condições de produção e reprodução de uma dada estrutura social."

A partir da compreensão das transformações socioambientais, no caso, as geradas pelo turismo no litoral do Iguape, podem-se propor medidas para a realização de um turismo sustentável naquela região.

Ao que se refere às características geoambientais, de acordo com o Instituto de Pesquisa e Estratégia Econômica do Ceará - IPECE (2004), esta área apresenta clima Tropical Quente Sub-úmido, com uma pluviosidade média de 1379.9mm/ano. A média de temperatura varia entre $26^{\circ}$ e $28^{\circ} \mathrm{C}$ e possui o período chuvoso de janeiro a maio. A área estudada é 


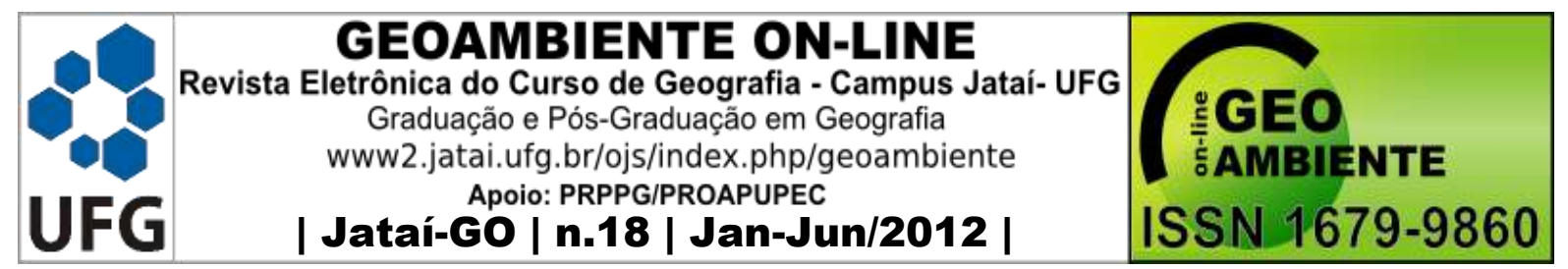

formada por um relevo de Planície Litorânea e Tabuleiros Pré-litorâneos, seus solos são formados por Areias Quartzosas, Alissolos, Solos Indiscriminados de Mangue e Planossolos. A cobertura vegetal é formada pelo complexo vegetacional da Zona Litorânea.

O distrito de Iguape está localizado no litoral leste do Município de Aquiraz a 38 quilômetros da capital cearense, que é o município de Fortaleza. É composto pelas praias do Presídio, Iguape, Barro Preto e Batoque. No entanto, somente as três primeiras possuem relevância do ponto de vista turístico, e são objetos de estudo deste artigo.

A praia do Presídio ${ }^{1}$ se destaca por seu passado histórico, pois serviu de prisão para prisioneiros trazidos em navios pelos holandeses. Esta praia atualmente é famosa por suas construções modernas, por suas fontes de água e pelos hotéis e pousadas disponíveis aos turistas.

A praia do Iguape ${ }^{2}$ possui um imenso campo de dunas fixas com densa vegetação, um lagamar com presença de manguezais e uma faixa de praia. Está situada na enseada formada pelas dunas da ponta do Iguape, cobertas por vegetação, onde podemos encontrar ressurgências de água doce. Famosa por sua importância histórica, devido o fato de ter sido centro da discussão política e administrativa acerca da instalação da primeira vila no Ceará.

A praia do Barro Preto ${ }^{3}$ possui uma extensa vegetação de mangues em torno do rio Catú que escoa da Lagoa da Encantada. No entorno da área se desenvolvem caminhos e passeios por meio de trilhas ecológicas.

\section{Breve histórico da ocupação do litoral do distrito de Iguape}

O início da intensificação da ocupação do distrito de Iguape se deu nas décadas de 1930 e 1940, com a chegada das primeiras famílias ao local. As casas eram de palha e não possuíam rede elétrica, os moradores dependiam dos recursos naturais para sua sobrevivência, como da pesca e do extrativismo vegetal. Nas décadas seguintes, as famílias vindas de Fortaleza começaram a ocupar o local construindo suas segundas residências.

Na década de 1970 o processo de ocupação se intensificou, em especial na faixa praial e na pós-praia. Neste período teve início a valorização daquele espaço, pois as famílias fortalezenses encontraram lazer e descanso nas praias do distrito de Iguape.

\footnotetext{
${ }^{1}$ Praia do Presídio: localiza-se a 17 km da Sede do Município de Aquiraz e 5 km da Sede do Distrito de Iguape (Jacaúna).

${ }^{2}$ Praia do Iguape: localizada a $44 \mathrm{~km}$ de Fortaleza, $18 \mathrm{~km}$ da Sede do Município de Aquiraz.

${ }^{3}$ Praia do Barro Preto - localiza-se a $2 \mathrm{~km}$ do Iguape e $20 \mathrm{~km}$ da Sede do Município de Aquiraz
} 


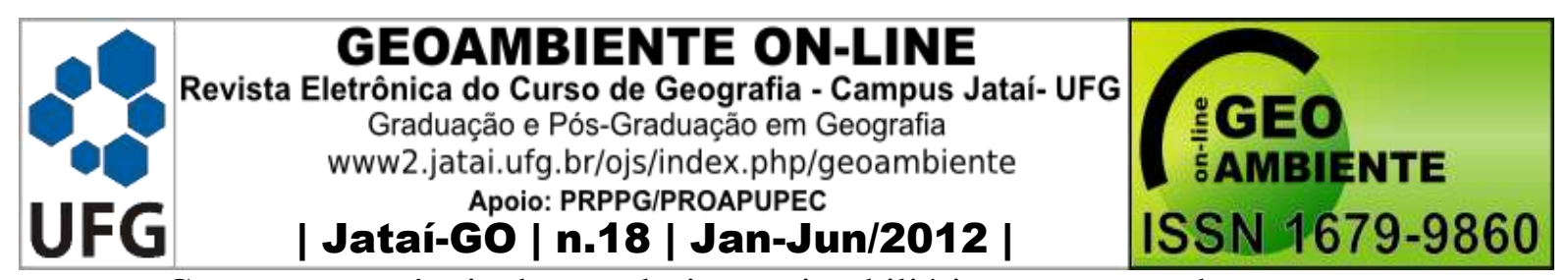

Como consequiência desta valorização imobiliária e ocupação deste espaço por novos agentes sociais, como visitantes e turistas, a dinâmica socioambiental da região foi modificada. Se antes a população nativa possuía uma relação de subsistência com os recursos naturais e tinha como principal atividade econômica o extrativismo vegetal e a pesca, a partir da chegada dos visitantes e turistas, esta relação foi alterada, pois a população local foi deslocada dos terrenos próximos à faixa praial, que passou a ser então o local onde os novos moradores instalaram suas segundas residências.

Com o aumento das segundas residências, elevou-se também a presença de uma população flutuante no local, que passou a exigir melhores condições de infraestrutura e serviços para atender suas necessidades, tais como pousadas, hotéis e restaurantes. A partir desta demanda, começou a ser construída no local toda uma infraestrutura visando atender à demanda turística que foi elevada. A oferta dessa infraestrutura e de serviços tem contribuído para o crescimento cada vez maior da procura por este destino.

\section{O turismo e as transformações socioambientais}

O aumento da população causou impactos sobre o meio ambiente, que não estava preparado para receber estas transformações de forma tão rápida. Em pouco tempo, o ambiente que era apenas usado para a subsistência de uma pequena população, é agora alterado e impactado pela ação antrópica de modo mais intenso, que já não respeita as características ambientais, realizando construções sobre dunas e aterrando mangues, prejudicando a biodiversidade e alterando o estado natural de equilíbrio dos ecossistemas.

O litoral é um ambiente de formação recente, desta forma, está em constante modificação, quer seja pela ação eólica, fluvial ou marinha. Assim, qualquer interferência antrópica implica sérios danos. Este ambiente, como é o caso do litoral do Iguape, é uma área de grande instabilidade ambiental, conforme afirma Silva (1998): os diferentes fatores que atuam nos processos geomorfogênicos, como as correntes marinhas, as oscilações do nível do mar e das marés, a arrebentação das vagas, a composição litológica, as feições do relevo, a hidrologia de superfície e a subterrânea, a ação dos agentes climáticos, principalmente a do vento, levam à formação de paisagens com alta instabilidade ambiental.

A dinâmica natural dos ambientes litorâneos é bastante intensa, devido a isso é preciso conhecer as inter-relações dos fluxos de matéria e energia que neles atuam a fim de 


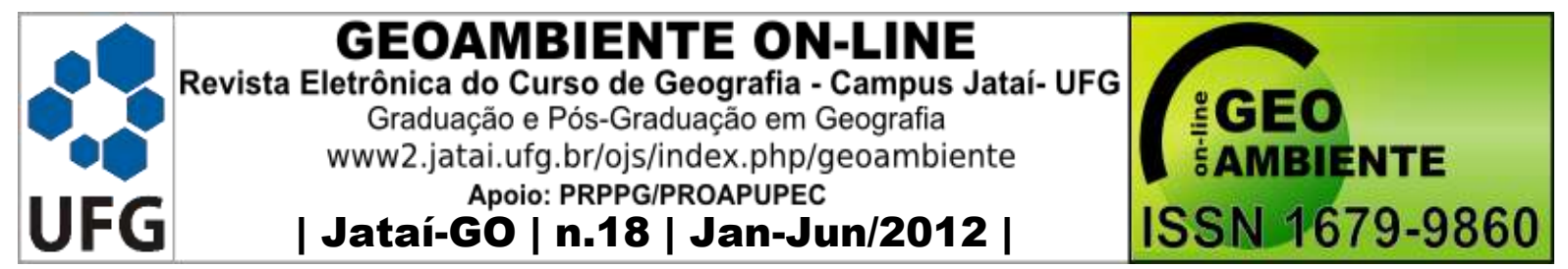

minimizar os efeitos danosos da ação antrópica, bem como criar diretrizes para o uso racional destes ambientes.

A forma de interagir com natureza dos novos residentes e turistas é bastante diferente daquela dos primeiros moradores, pois para os novos moradores, o meio ambiente é apenas um cenário, paisagem da qual ele se apropria momentaneamente para seu lazer e descanso, sem preocupar-se com os danos que possa estar causando. Pensam que quando compram os espaços, estão comprando o meio ambiente que está inserido nele e, desta forma, acreditam que podem transformá-lo como bem entenderem, não percebem que o meio ambiente e o ser humano estão interligados e que um depende do outro.

Outro tipo de transformação causada pelo advento do turismo em uma região ou localidade é o impacto social, que é menos perceptível visualmente do que o primeiro, mas não menos impactante. Quando os turistas e visitantes entram em contato com a população local, há um choque, principalmente entre as culturas. Muitas vezes a população local adota certos hábitos e costumes dos visitantes, para melhor integrar-se socialmente e também para ser aceita por eles.

Outra transformação que se pode citar está relacionada com a economia. Antes da chegada dos turistas, as atividades produtivas eram baseadas na pesca, no extrativismo vegetal e na agricultura de subsistência. Com a chegada dos turistas, passou a ser baseada no comércio e no turismo, apesar da pesca ainda subsistir, mesmo que não mais como principal atividade.

No litoral do distrito de Iguape o número de segundas residências é bastante elevado e, de acordo com a Prefeitura Municipal de Aquiraz, existe um número considerável de contribuintes não residentes no município. Há contribuintes de todos os estados do Brasil, incluindo a capital cearense, além de estrangeiros, principalmente oriundos de Portugal.

\section{Mudanças advindas com a alteração do fluxo turístico}

O turismo é uma atividade que muitas vezes se dá de forma insustentável, devido à falta de planejamento e gestão em determinados locais. Desta forma, os recursos naturais locais são exauridos e, assim, as belezas naturais que, na maioria das vezes, são o principal atrativo do local, são afetadas e por isso, o turismo entra em decadência naquele local, buscando novos espaços para apropriar-se. Sob esta ótica, o turismo é uma atividade predatória e itinerante. Porém, quando há um planejamento adequado, bem como a 


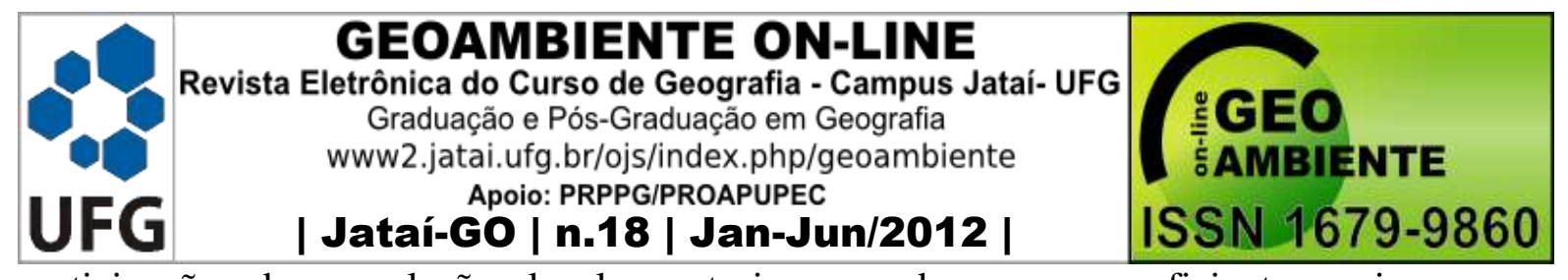

participação da população local, o turismo pode ser um eficiente meio para o desenvolvimento de uma região.

Nos últimos oito anos, o litoral do Iguape tem sofrido alterações na demanda turística. A maioria das agências de turismo excluíram o litoral do Iguape de seus roteiros turísticos, o que vem causando sérios danos à economia local, que se tornou dependente direta do turismo. Os pacotes turísticos que tem como destino o litoral leste são direcionados para outras áreas, em detrimentos do Iguape.

Um dos fatores apontados para tal fato é a construção de um Centro de Artesanato na rodovia CE-040, um pouco antes da entrada para o litoral do Iguape. Os ônibus de turismo ficam por ali mesmo, ao invés de entrarem no Iguape e dirigirem-se ao Centro das Rendeiras que ali se localiza. Isto tem gerado grandes prejuízos à população local, que tinha passado a viver basicamente das atividades relacionadas ao turismo, como artesanato, recepcionista, garçons, jangadeiros, bugueiros, entre outros.

O que acontece atualmente no litoral do Iguape é resultado de falta de planejamento turístico para a região. O local, que era bastante visitado por turistas até o início dos anos 2000, foi abandonado pelos guias turísticos devido a desentendimentos destes com alguns dos empreendedores locais, fazendo com que o destino Iguape fosse preterido pelas agencias de viagem. Como resultado, a demanda turística para o local diminuiu drasticamente.

Atualmente os turistas que vistam o litoral do Iguape são, basicamente, de Fortaleza e da Região Metropolitana, com raras exceções encontradas, principalmente, na Praia do Presídio. O litoral do Iguape não possui atualmente planos para um planejamento turístico sustentável, que conte com a participação da população local, bem como dos gestores públicos e privados a fim de transformar a realidade local e desenvolver a região.

Na contramão da diminuição do número de turistas na região, o litoral do Iguape tem sido alvo de grandes investimentos de capital estrangeiro nos últimos anos, principalmente, de origem portuguesa e espanhola. Um exemplo de um grande empreendimento turístico em construção naquela região é o Aquiraz Riviera, que pretende ser o maior empreendimento turístico de padrão internacional do Brasil. De acordo com a Prefeitura Municipal de Aquiraz, o Aquiraz Riviera possui um valor total estimado em US\$ 350 milhões, com área total de 300 de hectares e que será construído na praia de Marambaia, vizinho à praia do Presídio.

No projeto estão envolvidos o Banco Privado Português (BPP), o grupo hoteleiro Dom Pedro e o empresário brasileiro Ivens Dias Branco. Este empreendimento não é um caso 


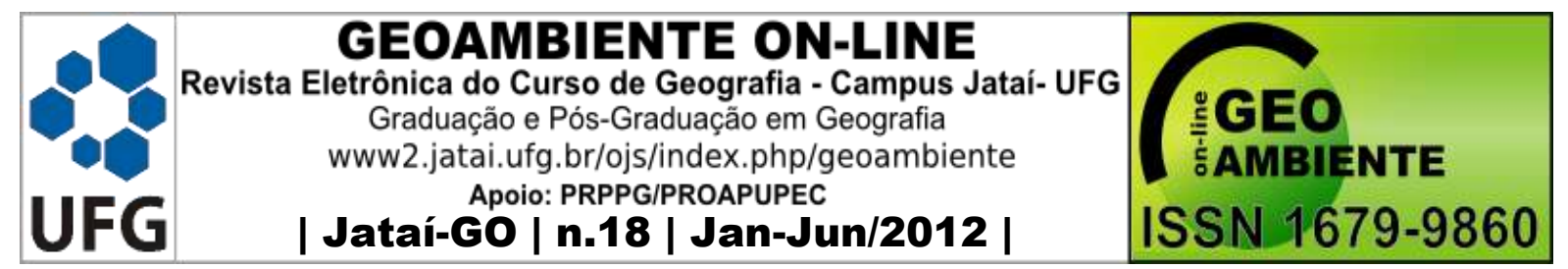

isolado, pois os investidores vêem naquela região uma das mais promissoras para o turismo no litoral leste cearense. Com a construção destes grandes empreendimentos turísticos no litoral do Iguape, espera-se que haja um melhor planejamento e estruturação do turismo na região, a fim de transformar novamente o litoral do Iguape em um dos locais mais visitados do litoral leste cearense, sem esquecer do meio ambiente, realizando-se, assim, um turismo sustentável naquela localidade.

Quando se fala destes grandiosos empreendimentos, difícil é não se perguntar qual o preço que o meio ambiente, e, por conseguinte, nós mesmos, teremos que pagar para que ele seja construído. Um projeto de tamanhas dimensões certamente acarretará impactos negativos ao meio ambiente, porém, muitas vezes estes impactos são mascarados e menosprezados pelos gestores, alegando que seus benefícios serão maiores que os prejuízos. Até quando será permitido tal desenvolvimento a qualquer preço, mesmo que este preço seja a nossa própria sobrevivência e a das futuras gerações?

Assim sendo, acredita-se que uma das soluções para tal problemática que se apresenta no litoral do Iguape seria a realização de um turismo sustentável, no qual a população local, os turistas, os empreendedores e os organismos governamentais atuassem juntos e de forma participativa, onde cada um dos interesses dos envolvidos seriam discutidos tendo em vista sempre a questão socioambiental, uma vez que o principal atrativo turístico daquela localidade são os recursos naturais, sem eles, o turismo estará severamente prejudicado, e assim, o modo de vida da população que dele depende diretamente.

\section{Considerações Finais}

Após observamos algumas das transformações ocasionadas pelo turismo no distrito de Iguape nos últimos anos, cabe aqui fazermos uma reflexão sobre a viabilidade da implantação de um turismo sustentável naquela região, respeitando tanto os interesses dos residentes como dos turistas e empreendedores, mas sem esquecer o meio ambiente.

Será que as partes envolvidas estariam interessadas em discutir medidas para se alcançar o desenvolvimento sustentável? Será que todos estariam dispostos e preparados a ceder?

A implantação de um turismo sustentável no litoral do Iguape seria uma das formas de se minimizar os impactos negativos do turismo, pois com o turismo sustentável o 


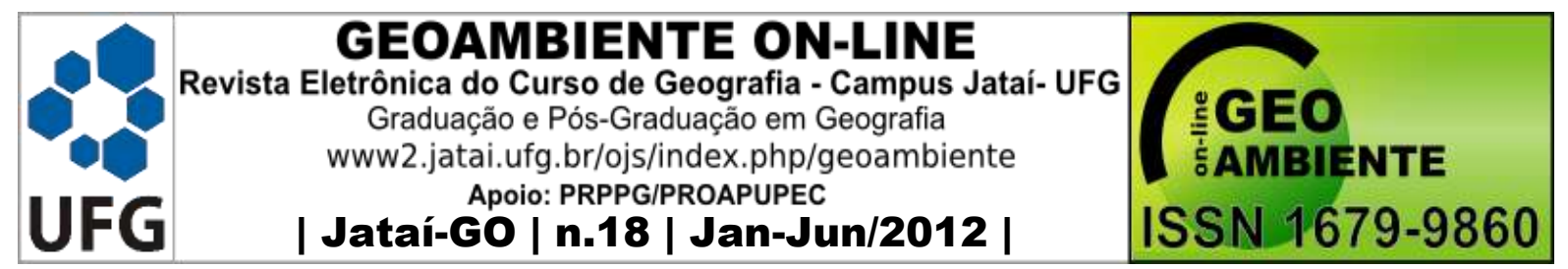

desenvolvimento econômico da região estaria assegurado, porém sem comprometer o meio ambiente, e, por conseguinte, as futuras gerações.

Com base nos questionários e entrevistas aplicados aos turistas, residentes e empreendedores locais, observa-se que já existe uma preocupação por parte dos envolvidos com os impactos gerados pelo turismo ao meio ambiente local, mas essa preocupação ainda não é suficiente para uma mudança de atitude.

Os turistas reclamam da sujeira das praias, da poluição dos mangues, da descaracterização da paisagem devido a construções irregulares, os moradores reclamam da poluição sonora causada pelos turistas, do trânsito de veículos na faixa de praia, da falta de oportunidades dentro da cadeia produtiva do turismo, os empreendedores reclamam da falta de investimentos públicos em divulgação do destino turístico, da falta de infraestrutura adequada para receber os turistas.

Muitos são os interesses em jogo, mas acredita-se que uma forma de se congregar esses interesses seja através da implantação de turismo sustentável naquela localidade e para se alcançar esta sustentabilidade seria primeiramente necessária a conscientização, tanto da população local como dos grandes empresários acerca da importância da preservação e conservação do meio ambiente, para o turismo, uma vez que, grande parte do potencial turístico do litoral é proveniente das belezas naturais, ou seja, fazem parte dos recursos naturais. Quando estes recursos são degradados, tanto perde o meio ambiente, como a população local e os grandes empresários, mesmo porque inviabiliza o próprio turismo local.

A partir da tomada de consciência, devem-se propor medidas efetivas que viabilizem a realização de um turismo sustentável na região, como uma maior fiscalização na liberação de licenças e construção de novos empreendimentos turísticos, realização de oficinas de capacitação profissional para a população local, implantação de medidas que incentivem os empreendimentos a minimizar seus impactos ambientais, entre outras.

Desta forma, pode-se dizer que no litoral do distrito de Iguape, o desenvolvimento sustentável e o turismo devem caminhar juntos, pois são interdependentes, uma vez que o turismo depende dos recursos naturais, para atrair turistas e, por conseguinte, investidores, gerando o desenvolvimento. Se este desenvolvimento não for sustentável, em pouco tempo os recursos naturais estarão esgotados e as belezas naturais, que constituem o atrativo turístico por excelência, não existirão mais e, desta forma, o turismo estará severamente prejudicado, bem como o desenvolvimento da região. 


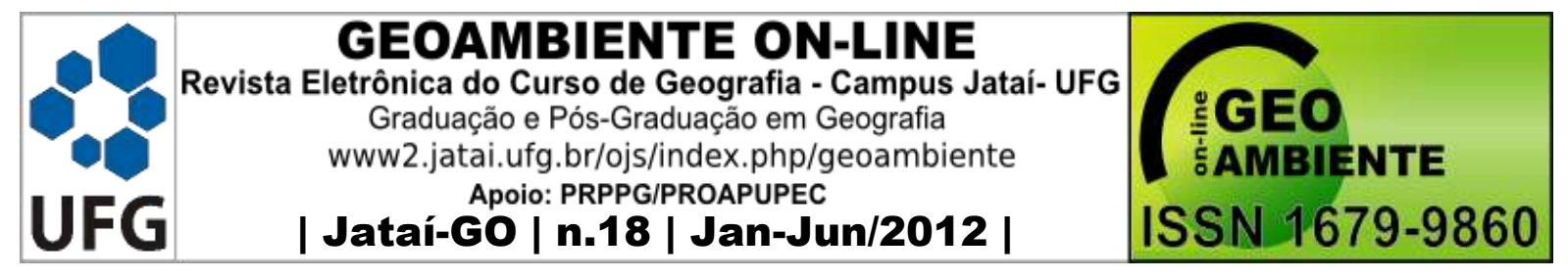

\section{REFERÊNCIAS BIBLIOGRÁFICAS}

ANSARAH, M. G. dos R. (Org.). Turismo. Como aprender, como ensinar. São Paulo: Editora SENAC, 2001.

BARRETTO, Margarita. Planejamento e organização em turismo. 9 ed. Campinas: Papirus, 1991.

BARRETTO, Margarita. Manual de iniciação ao estudo do turismo. 13 ed. rev. e atual. Campinas: Papirus, 2003.

BENI, M. C. Como certificar o turismo sustentável? Revista Espaço Acadêmico. Ano IV, no 37, Junho/2004.

CORIOLANO, Luzia Neide Menezes Teixeira (Org.). Turismo com ética. Fortaleza: Ed. UECE, 1998.

CORIOLANO, Luzia Neide. M. T; LIMA. Luiz Cruz (orgs.). Turismo comunitário e responsabilidade socioambiental. Fortaleza: EDUECE, 2003.

CORIOLANO, Luzia N. M. T. A Utopia da Sustentabilidade no Turismo. In: CORIOLANO, Luzia N.M.T.; VASCONCELOS, F. P. (Org.). Turismo e a relação Sociedade-Natureza: realidades, conflitos e resistências. Fortaleza: UECE, 2007.

CHAVES, Gilmar. Ceará de corpo e alma: um olhar contemporâneo de 23 autores sobre a terra da luz. Fortaleza: Instituto do Ceará, 2002.

CRUZ, Rita de Cássia Ariza da. Introdução à Geografia do Turismo. São Paulo: Roca, 2001.

CUNHA, Sandra Baptista da; GUERRA, Antonio Jose Teixeira. A questão ambiental: diferentes abordagens. Rio de Janeiro: Bertrand Brasil, 2003.

IPECE. Perfil Básico Municipal: Aquiraz. Fortaleza, 2007.

LEFF, E. Saber Ambiental: sustentabilidade, racionalidade, complexidade, poder. $5^{\mathrm{a}}$ ed. Petrópolis, RJ: Vozes, 2001.

LIMA, P. C. S. Desenvolvimento Local e Turismo no Porto de Galinhas-PE. Dissertação (Mestrado em Arquitetura e Urbanismo) - Universidade de Brasília, Brasília, 2006.

MENDONÇA, Francisco. Geografia e Meio Ambiente. 6.ed. São Paulo: Contexto, 2002.

MENDONÇA, Francisco de Assis. Geografia socioambiental. Terra Livre. São Paulo n. 16 p. 139-158 1o semestre/2001.

MOTTA, Ronaldo S.. Valorando a natureza: análise econômica para o desenvolvimento sustentável. Rio de Janeiro: Campus, 1994. 


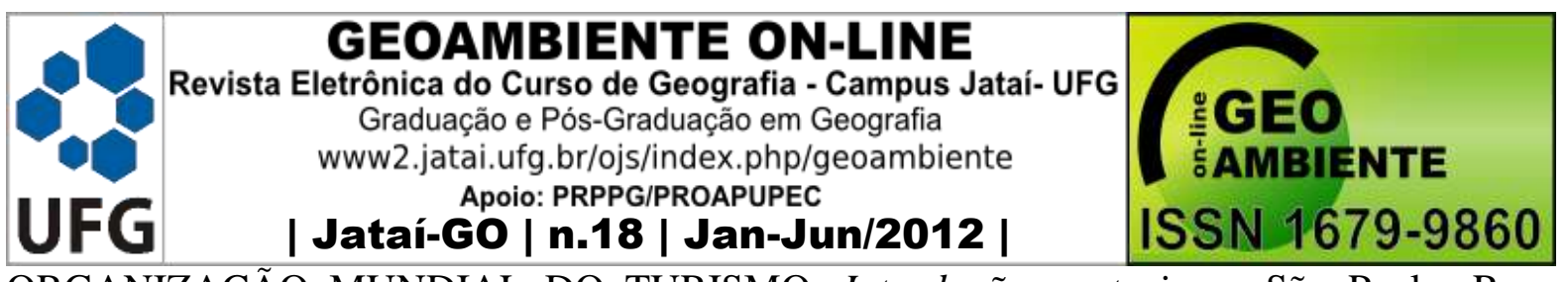

ORGANIZAÇÃO MUNDIAL DO TURISMO. Introdução ao turismo. São Paulo, Roca, 2001. Tradução de Dolores Martin Rodriguez Córner.

ORGANIZAÇÃO MUNDIAL DO TURISMO. Lo que todo gestor turístico debe saber. Madrid (Espanha): OMT, 1995.

RABAHY, W. de A. Fundamentos econométricos e estudos econômicos no Planejamento turístico. São Paulo: Esc Comunic \& Artes, 1988.

RODRIGUES, Arlete Moysés. A produção e o consumo do espaço para o turismo e a problemática ambiental. In: YÁZIGI, Eduardo; CARLOS, Fani; CRUZ, Rita de Cássia Ariza da. (orgs.) Turismo, espaço, paisagem e cultura. São Paulo: HUCITEC, $2^{\mathrm{a}}$ ed., 1996.

SACHS, Ignacy. Caminhos para o desenvolvimento sustentável. Rio de Janeiro: Garamond, 2002.

SANTOS, Milton. Metamorfoses do espaço habitado. São Paulo: Hucitec, 1988.

SILVA, E.V. da. Geoecologia da Paisagem do Litoral Cearense: uma abordagem ao nível regional e tipológico. Tese para professor titular, Centro de Ciências, UFC, 1998.

VEYRET, Y. Géoenvironment. Paris. Sedes, 1999. 